Reprod. Nutr. Dévelop., 1987, 27 (1 B), 199-200.

\title{
Matière sèche ingérée et performance des agnelles laitières de race Comisana et Sarda au pâturage irrigable de Festuca arundinacea
}

\author{
U. FRANCIA, L. TAIBI (*), S. PUPPO, S. TERRAMOCCIA, A. PELOSI (*)
}

Sezione Foraggi e Mangimi, Via Salaria 31, Monterondo Scalo (RM), Italia.

(*) Sezione di Foggia.

Summary. Three cultivars of Festuca ar. (Manade, Festal, Ludion) were grazed by 264 ewes lambs, 138 of the Sarda breed and 126 of the Comisana breed. A rotation technique was used : from April to September 1983 (1st period), the Comisana ewes grazed, and from September 1983 to January 1984 (2nd period), the Sarda ewes grazed on the same blocks. In the first period, the average dry matter grazed daily was 103.2, 105.5 and $1192 \mathrm{~g} / \mathrm{kg} \mathrm{P} \mathrm{P}^{0.75}$ for each cultivar, respectively. In the second period, 110.7, 103.6 and $62.4 \mathrm{~g} / \mathrm{kg}$ was grazed.

La connaissance de la quantité d'herbe ingérée au pâturage est très importante pour améliorer la production des animaux et l'exploitation de la pelouse. De nombreux auteurs ont cherché des méthodes d'estimation (Tissier et al., 1975 ; Walters et al., 1979 ; Wanyoike et al., 1981 : Martillotti et al., 1984).

Matériel et méthodes. Au printemps de 1982, nous avons semé trois variétés de Festuca arundinacea (Manade, Festal, Ludion) sur 9 parcelles de 2 ha. Ces prairies ont été pâturées par un troupeau de 126 agnelles de race Comisana (poids moyen $24,3 \mathrm{~kg}$ ) et de 138 agnelles de race Sarda (poids moyen $26,8 \mathrm{~kg}$ ) du 6 avril au 23 septembre 1983, puis seulement par les agnelles Sarda jusqu'au 27 janvier 1984. La quantité d'herbe ingérée a été estimée par différence entre les quantités présentes à l'entrée des animaux, (fauche de 4 cages de $1 \mathrm{~m}^{2} /$ ha) et à la sortie des animaux. Le nombre d'exploitations a été de 5 ou 6 pendant la première période et de 2 ou 3 pendant la deuxième (tabl. 1), les animaux étant pesés au

TABL. 1. - Production, consommation et composition des trois variétés de Festuca arundinacea.

\begin{tabular}{|c|c|c|c|c|c|c|}
\hline & \multicolumn{3}{|c|}{ Printemps-Eté } & \multicolumn{3}{|c|}{ Automne } \\
\hline & $\mathrm{M}(1)$ & $\mathrm{F}$ & $\mathrm{L}$ & M & $\mathrm{F}$ & L \\
\hline Nombre d'exploitations & 6 & 5 & 5 & 2 & 3 & 3 \\
\hline Intervalle moyen (j) & 23 & 24 & 25 & 53 & 40 & 34 \\
\hline Quantité d'herbe : kg MS/ha & & & & & & \\
\hline $\begin{array}{l}\text { Offerte } \\
\text { Non consommée }\end{array}$ & $\begin{array}{r}9680 \\
740\end{array}$ & $\begin{array}{r}7300 \\
360\end{array}$ & $\begin{array}{r}8180 \\
910\end{array}$ & $\begin{array}{r}5400 \\
330\end{array}$ & $\begin{array}{l}7330 \\
2840\end{array}$ & 1970 \\
\hline $\begin{array}{l}\text { Charge moyenne brebis } / \text { ha } \\
\text { Quantité ingérée } \mathrm{g} \mathrm{MS} / \mathrm{kg} \mathrm{P}^{0.75}\end{array}$ & 42 & 32 & 29 & 11 & 16 & 18 \\
\hline $\begin{array}{l}\text { Herbe } \\
\text { Foin }\end{array}$ & $\begin{array}{r}103 \\
20\end{array}$ & $\begin{array}{r}106 \\
24\end{array}$ & $\begin{array}{r}119 \\
29\end{array}$ & $\begin{array}{r}111 \\
20\end{array}$ & $\begin{array}{r}104 \\
21\end{array}$ & $\begin{array}{l}62 \\
19\end{array}$ \\
\hline $\begin{array}{l}\text { Total } \\
\text { Herbe }\end{array}$ & 123 & 130 & 148 & 131 & 125 & 81 \\
\hline Teneur MS \% & 30,7 & 29,7 & 32,0 & 23,0 & 28,1 & 28,0 \\
\hline Matières azotées \% MS & 15,2 & 16,2 & 13,0 & 18,0 & 17.4 & 17,6 \\
\hline Cellulose brute \% MS & 26,0 & 25,0 & 27,0 & 26,0 & 26,0 & 25,6 \\
\hline Digestibilité MO & 0,64 & 0,65 & 0,61 & 0,65 & 0,65 & 0,66 \\
\hline
\end{tabular}

Variétés: $\mathrm{M}$ : Manade, $\mathrm{F}$ : Festal, L : Ludion. 
début et à la fin de deux périodes de pâturage. La charge en animaux (tabl. 1), était en excès pour obtenir une utilisation totale de l'herbe disponible ; on a donc distribué un peu de foin de Festuca ar. variété Manade $110,5 \%$ de matières azotées, $31,2 \%$ de cellulose brute, digestibilité de la matière organique : 56,7$)$ y compris pour améliorer l'état sanitaire des animaux atteints de diarrhée. Sur les échantillons de fourrage desséchés (4 pour chaque parcelle et pour chaque passage) ont été déterminées la composition chimique et la valeur nutritive (tabl. 1).

Résultats et discussion. L'herbe offerte aux animaux avait une teneur en matière sèche élevée mais très variable (coefficient de variation de 15 à $30 \%$ selon les parcelles). Les teneurs en cellulose brute et la digestibilité de la matière organique étaient moins variables.

Les quantités moyennes d'herbe ingérées ont été de 103,106 et $119 \mathrm{~g} / \mathrm{kg}$ $\mathrm{P}^{0,75}$ au cours de la période de printemps et d'été, respectivement pour les variétés Manade, Festale et Ludion et de 111, 104 et 62 pour la période d'automne. Compte tenu de la consommation de foin, ces valeurs sont relativement élevées. Cela peut être dû à la forte teneur en matière sèche de l'herbe et aussi à une évaluation par défaut de la quantité d'herbe non consommée. Les agnelles ont gagné en moyenne $39 \mathrm{~g} /$ jour au cours de la première période et $23 \mathrm{~g}$ au cours de la deuxième.

Martillotti F., Malossini F., Tripaldi C., Francia U., 1984. Ann. Sper. Zootech., 1, 53-63.

Tissier M., Béchet G., Molénat G., 1975. Ann. Zootech., 24, 595-602.

Walters R., Evans E. M., 1979. Grass Forage Sci., 34, 37-44.

Wanyoike M., Holmes W., 1981. Grass Forage Sci., 36, 221-225. 